\title{
Modelling the profitability of reverse mortgage loans with life-long annuity payments
}

\author{
Elena Kuzmina ${ }^{1 *}$ and Andrei Ianin ${ }^{2}$ \\ ${ }^{1}$ Higher School of Economics, Soyuza Pechatnikov Str. 16, 190121, St. Petersburg, Russia \\ ${ }^{2}$ Graduate School of Management, St. Petersburg University, Volkhovskiy Per., 3, 199004, St. \\ Petersburg, Russia
}

\begin{abstract}
The article deals with the economic mechanism of reverse mortgage as a loan product aimed at raising the welfare of senior citizens who own real estate, for organic farming and soil management. The article discusses the financial and historical aspects of the implementation of the reverse mortgage instrument, as well as defines a potential of implementation of this instrument in Russia. Having identified the potential, the authors also mentioned the factors that could prevent Russian banks from adopting this mechanism. The article addresses one specific factor - absence of adequate instruments to predict and evaluate financial performance of reverse mortgage instruments. Consequently, the aim of the current paper is to create a mathematical model of reverse mortgage loan; specifically, current paper focuses on reverse mortgage loan with lifelong annuity payments. In order to derive such model, the authors adopted a perspective, according to which loans are perceived as specific products present on an open market. As a result, we have obtained a model that allows lenders to calculate expected gains from reverse mortgage loans with respect to unknown loan span and varying demand, thus diminishing the uncertainty about reverse mortgage properties and making this financial product more attractive and for agricultural planning and economic, agricultural logistics and transport, et al.
\end{abstract}

\section{Introduction}

The majority of developed countries including the US, the EU and Japan had encountered a problem of an aging of the population. Even though it appeared later, the same problem emerged in Russia. This issue leads to several considerable economic repercussions that have to be addressed by the government. One of such problems (probably, the most important one) is an increase of pressure put on government budget by an increasing pension fund; that results in a decrease in retirees' income. The income decrease results in a reduction of aggregate demand, what leads to a decrease in total sales of goods and services slowing down economic growth. The economic problems also may be followed by social and political issues caused by a fall of total welfare.

\footnotetext{
* Corresponding author: andreyyanin1995@mail.ru
} 
Various approaches that allow to cope with the aging population issues exist. However, no single approach can be considered a universal solution; hence, governments should adopt complex programs that tackle the problems under different angles. Though, no matter the chosen course of action, possible solutions should preferably tackle the initial problem (low welfare pf elderly people) while lowering state expenditures. Despite of the fact that these objectives may seem mutually exclusive, there are several financial instruments that may allow to reach them both. These instruments often deal with asset conversion: using property that is already in pensioners' possession to generate some liquid income. Current study focuses on one of such instruments - reverse mortgage.

Reverse mortgage is a group of loan products that have one major peculiarity in common: real estate owned by a borrower is used a pledge for the loan that is received by a borrower as an annuity, line of credit, one-time payment or a combination. In addition, the realty is being left in possession by the borrower until they die (or the loan expires). Lifelong reverse mortgage is a particular specification of loan when a borrower obtains an annuity payment each period (typically a month or a quarter) until a termination event takes place. The termination event is an occurrence when bank's obligations (on paying the annuities) are considered to be accomplished; basically, these occurrences deal with the borrowers dying or leaving their residences. Once the loan is terminated, a real estate is sold and the money received this way is used to cover the loan and the interest. The remaining money is then transferred to a lender (or their heirs). One of the peculiarities of reverse mortgage loan is that a bank does not receive a right of possession over a lender's real estate: it only serves as a collateral, meaning that a bank is not allowed to dispose of lender's property other than in case of loan termination.

The term "reverse mortgage" was initially created in the US and the first reverse mortgage loan was issued in 1961 by a bank Deering Savings and Loan in the city of Portland, Maine [CFP Bureau, 2012]. In the beginning, reverse mortgages were primarily issued with governmental support. They were subsidized by state governments or local administrations and allowed poor pensioners to borrow money with very low interest rates. The first governmental reverse mortgage program was created by authorities of Oregon state in 1963; in 1978 a similar program was started by Wisconsin. In the mid-80s reverse mortgages boomed, as real estate prices soared: most American commercial banks started providing reverse mortgage loans, making them a full scale financial product.

Positive experience of the US motivated banks in other countries (mostly in Europe and East Asia) to create their own reverse mortgage programs. Currently, Russian authorities are also approbating reverse mortgage programs "as a test"; meaning, that the loans are only being issued by a specific governmental organization in low volumes. Organization, supervising reverse mortgage in Russia is called Agency of Restructuring Mortgage Loans (ARML). ARML funds loans, chooses their specification, sets limitations and requirements for borrowers and collateral. The scheme of mortgage loan obtaining set by ARML is the following: a pensioner contacts a bank and expresses their desire to receive a loan; as a part of the request, a borrower should choose one of the available payment options (currently 2 options are available: monthly annuity payments and single payment); next, if a request is approved, a loan is being issued (with using borrower's real estate as a collateral); then, when the loan is terminated, collateral is sold covering the loan and the interest (remaining money is given to borrowers/their heirs). This model is very similar to the one that exists in the US.

However, there are several factors that limit further development of reverse mortgage loans in Russia. While some of them could be addressed only by the government (like legislation), others are connected with banks' issues. For instance, before adopting a financial product, commercial banks have to consider whether it will be profitable or not: that is mainly done with the help of economic modelling. Unfortunately, reverse mortgage 
is very different from other loan types present on Russian market, which makes modelling and risk management difficult. Consequently, banks are unlikely to adopt a product for which they cannot calculate expected gains and losses.

Therefore, the aim of this paper is to present a mathematical framework that will help lenders to calculate their expected profits from reverse mortgage loans, thus making this instrument more attractive for commercial use.

\section{Methodology}

In accordance with the goal of the current study, we should create a mathematical framework that would indicate some expected financial result of a mortgage loan operation, if the required parameters are known. Expected gains from financial assets are vital for bank's decision making process; therefore, eliminating or reducing an information absence would be necessary for any economic agent in order to consider reverse mortgage loans as an investment opportunity.

The overall framework of reverse mortgage valuation was derived from the paper of Lee et al. [Lee et al., 2012]. Since loan can be viewed as a product present on an open market, loans share some of the characteristics of goods common for microeconomics. "Price" of a loan is, essentially, the interest which is to be paid by an agent if they want to take a loan. Therefore, on the one hand, interest is one of the key identifiers of supply and demand volume; on the other hand, interest is also the result of supply-demand interaction on the loan market. Keeping this logic in mind we propose to model reverse mortgages gains as a profit received by a bank from the loans issued, given the interest rate. This framework will allow to capture the effect of the law of demand: increased interest enhances gains from one loan, but decreases the number of loans issued. Hence, the system of equations should have 2 main parts representing supply side (where the interest rate is set) and the demand side (which reacts to the interest rate).

Supply side equation represents profit maximization. In this equation we aimed to capture the effects linked with the unique character of reverse mortgages: unlike other loans reverse mortgages may be not fixed in time (life-long mortgages), what results in additional modelling difficulties. For instance, since the loan is terminated at death, we should include mortality forecast in our formula. A Lee-Carter model was used, in order to represent the effects of mortality rates changing over time.

Demand side equation represent utility maximization. In this part we demonstrated the effect of reverse mortgage loan on utility connected with different types of consumer incentives.

\section{Modelling results}

Reverse mortgage can be considered a new product on the Russian market. Introduction of a new product requires existence of economic incentives for all the involved agents: reverse mortgage has to be rewarding both for borrowers and creditors. Therefore, there are certain limitations introduced for the parameters representing agents' stimuli at the considered market. These limitations will also be referred to as "conditions of participation".

To start with, the main condition of participation for a bank is profit acquisition. In the general form (without a detailed discussion), the formula representing this parameter looks the following way:

$$
\pi=\sum((S+I(S))-S-C)
$$


Where $\pi$ is the profit, $\mathrm{S}$ - loan, I - interest income (which is a function of credit body), C operational and transactional costs. Basically, the profit of a bank is the total difference between the interest income gained and the costs encountered. The next step (required to broaden our understanding of the formula) is the definition of an interest income I(S) [Chen et al., 2010]. The formula of an interest income is heavily dependent on a type of payment of a credit. Mathematically, all types of payments can be regarded as the subtypes of 2 payment methods: annuity payments and line of credit. In the current paper we are studying annuity payment method only. Creation of a model with line of credit payments requires using several stochastic parameters that describe a will of an $i$ individual to borrow an unknown amount of money in a period $\mathrm{n}$, what results in a considerable complication of a model [Kogure et al., 2014].

Reverse mortgage represents an example of annuity-due credit, which is a type of loan, when payments are made in the beginning of a period. However, we cannot use a standard annuity-due payments formula due to the fact that standard formula is used in the cases when an overall size of a loan is known, while a payment size should be calculated [Kellison, 2006]. In case of reverse mortgage, the payment size is set in a contract (hence, it is known), but the overall credit sized is undefined. Therefore, we have altered the formula the following way:

$$
L_{b}=A * \frac{\left(1+\frac{i}{12}\right)^{n}-1}{\left(1-\frac{1}{1+\frac{i}{12}}\right)}(2)
$$

Let us suppose that the payments are made monthly. Then $L_{b}$ denotes an overall size of the loan (with interest), A - monthly annuity payment, $\mathrm{i}$ - yearly interest rate, $\mathrm{n}$ - number of months passed since the beginning of payments. Taking into account formula (2), we can derive a new bank profit formula:

$$
\pi=\sum_{n} A\left(\frac{\left(1+\frac{i}{12}\right)^{n}-1}{1-\frac{1}{1+\frac{i}{12}}}-n\right) * \sum_{t=0}^{n-1} \frac{\xi}{(1+r)^{\frac{t}{12}}}-\mathrm{C} \text { (3) }
$$

Where $\mathrm{r}$ is a discount rate, $\mathrm{n} \in[1 ; \mathrm{T}]$ (where $\mathrm{T}$ is a number of monthly annuity payments made), $\xi$ is a share of annuity payments made (with interest) in period $t$ with respect to total loan volume: calculation of this variable is not a trivial task. Hence, we will use proxy instead; our simulations indicate that the usage of the proxy variable provides us with comparable results when the rate is below $\sim 20 \%$ :

$$
\frac{1}{n} \sum_{t=0}^{n-1} \frac{1}{(1+r)^{\frac{t}{12}}}
$$

Formula (3) is valid for the cases, when the terms of credit are known and predefined. However, the most popular types of annuity payments (as it was discussed in the previous parts of the work) are life-long. Since lifespan of a borrower is unknown when the credit is issued, it is impossible to calculate precisely cash flows that a bank can obtain from reverse mortgage. Therefore, we should add probabilistic member to formula (3), in order to measure the expected lifespan of a borrower [Nakajima and Telyukova, 2017]. 
Expected lifespan is measured with the help of mortality rates. Mortality rate is a statistical indicator that is calculated according to the following formula:

$$
\mathrm{m}_{\mathrm{x}}=\frac{\mathrm{d}_{\mathrm{x}}}{\text { Live }_{\mathrm{x}}}(4)
$$

where $\mathrm{m}$ denotes mortality rate, $\mathrm{d}$ - number of people died in period $\mathrm{x}$ and Live - average number of people alive in period $\mathrm{x}$.

Mortality rates table may allow to calculate the expected lifespan of an individual. On the other hand, such approach has a clear drawback: lifespan is calculated using historical data [Shao et al., 2015]. Reverse mortgage, as a credit, covers several consequential periods in time. Thus, banks are interested in individual's lifespan not in current period of time, but in future. Therefore, we should use other method of identification of life expectancy: LeeCarter model. This model uses stochastic modelling to forecast expected lifespan.

$$
\ln \left(\mathrm{m}_{\mathrm{x}, \mathrm{t}}\right)=\mathrm{a}_{\mathrm{x}}+\mathrm{b}_{\mathrm{x}} \mathrm{k}_{\mathrm{t}}+\mathrm{e}_{\mathrm{x}, \mathrm{t}}
$$

where $\mathrm{m}$ is mortality rate, a - average age specific mortality rates, $\mathrm{k}-\mathrm{a}$ trend vector of mortality, $\mathrm{b}$ - a vector that describes mortality change for a specific age group, e - normally distributed error, $\mathrm{x}$ and $\mathrm{t}$ subscripts refer to age group and time period accordingly.

De facto, all the vectors located in right-hand side of the equation are initially unknown. So, the parameters should be evaluated with the following formulas:

$$
a_{x}=\frac{1}{N} * \sum_{t=1}^{N} \ln \left(m_{x, t}\right)
$$

Formula (6) allows to estimate the vector a. Next, authors suggest estimating $b_{\mathrm{x}} \mathrm{k}_{\mathrm{t}}$ member. They state that it is impossible to use method of least squares in the case, so they propose using singular value decomposition.

$$
\mathrm{M}=\mathrm{U} \Sigma \mathrm{V}^{*}(7)
$$

Where $\mathrm{M}$ is a decomposition matrix (in this case $\ln (\mathrm{m})-\mathrm{a}$ ), $\mathrm{U}$ - matrix of left singular vectors, $\mathrm{V}$ - conjugate transposed matrix and $\Sigma$ is the matrix of singular numbers.

As a result, Lee-carter model produces a matrix (or a vector) with mortality rates for different age groups. Consequently, returning to formula (3), we can rewrite the boundaries for the variable $\mathrm{n}$ the following way (for the case of life-long annuity payments):

$$
n \in\left[1 ; E\left(l_{x}\right)\right], \text { where } E\left(l_{x}\right)=\text { age }+\gamma \sum_{x=\text { age }}^{x} \prod_{j=a g e}^{x}\left(1-\psi m_{j}\right)
$$

Where $\mathrm{l}_{\mathrm{x}}$ - lifespan of an individual from $\mathrm{x}$ age group, age - current age of a borrower (when the loan is issued), $\gamma$ - size of an age category (in number of years), $\psi$ - correcting coefficient. Mathematically, mortality rate is not equal to probability of dying. Correcting coefficient takes this discrepancy into account and transforms mortality rate into probability. $\psi=\frac{\text { Live }_{\mathrm{x}}}{\mathrm{O}_{\mathrm{x}}}$, where $\mathrm{O}-$ number of people alive in the period $\mathrm{x}$. Given the difference between indicators, $\psi<1$ for every age category (except for the last age group, where mortality rate is $<1$, but probability of dying $=1$ ).

So, having added the expected value to the model, we are now facing the uncertainty. At the current stage we should also recall some peculiarities of reverse mortgage. This type of 
loan does not have a property of regress. It means that the borrower can only pay for the claims from the creditor with the assets that are listed in a contract, signed when the credit is issued. In case of reverse mortgage, a borrower uses his/her real estate as such asset. Hence, a creditor can only cover its expenses if they do not exceed property value (otherwise reverse mortgage is detrimental). Therefore, with non-fixed credit terms a bank faces a risk that the loan could exceed property value. We should express this in the formula: an increase in lifespan of an individual has an effect of growth of loan size, as well as an effect of rise of probability of loan exceeding lien property value.

$\mathrm{E}(\pi)=\sum(1-\mathrm{p}) \mathrm{A}\left(\frac{\left(1+\frac{\mathrm{i}}{12}\right)^{\mathrm{n}}-1}{1-\frac{1}{1+\frac{\mathrm{i}}{12}}}-\mathrm{n}\right) * \frac{1}{\mathrm{n}} \sum_{\mathrm{t}=0}^{\mathrm{n}-1} \frac{1}{(1+\mathrm{r})^{\frac{\mathrm{t}}{12}}}-\mathrm{p}\left(\widehat{\mathrm{L}_{\mathrm{b}}}-\mathrm{h}_{\mathrm{T}}\right) * \frac{1}{(1+\mathrm{r})^{\frac{\hat{n}}{12}}}-\mathrm{C}(9)$

Where $\widehat{\mathrm{L}_{b}}$ is an estimate of the loan value "from above" (an estimate that is derived when the lifespan exceeds the expected value) and $\hat{n}$ is a duration of the loan which corresponds to this estimate, $\mathrm{h}_{\mathrm{T}}$ - value of the property in the terminal period, $\mathrm{p}$ - probability of excess of loan value over real estate price. Here, $\mathrm{p}$ is a function from mortality rate and $\frac{\partial \mathrm{p}}{\partial \mathrm{m}}>0$ [Lee et al., 2012].

Nonetheless, duration of a loan is not the only argument of the probability function. The probability also depends on some other factors. Firstly, market factor; this can be evaluated with the help of studying indicators of the property market, such as price per square meter $\mathrm{h}_{\mathrm{p}}$; secondly, another category includes factors linked with the state of a property, f.e. wear level $h_{c}$. Consequently, $p$ is a function of several arguments:

$$
\mathrm{p}=\mathrm{f}\left(\mathrm{m}, \mathrm{h}_{\mathrm{p}}, \mathrm{h}_{\mathrm{c}}\right) \text { при } \frac{\partial \mathrm{p}}{\partial \mathrm{m}}<0, \quad \frac{\partial \mathrm{p}}{\partial \mathrm{h}_{\mathrm{p}}}<0, \quad \frac{\partial \mathrm{p}}{\partial \mathrm{h}_{\mathrm{c}}}>0
$$

Next, after we have studied the supply-side of the market, we should also consider incentives of the borrowers. According to microeconomic theory, the foundations for a consumer choice can be expressed with the help of utility function. Basically, main motive of a consumer choice is utility maximization; main tool of maximization is consumption. Hence, the utility function is a function of consumption of goods and services $U=f(c)$, where $\mathrm{U}$ denotes utility and $\mathrm{c}$ is a vector of consumed goods/services.

Empirical data demonstrates that consumers often accumulate more assets than they can possibly consume; thus, economists outline at least one more stimulus for consumers: stimulus of bequest accumulation [Lockwood, 2012]. The idea of this motive is the following: individuals gain utility from possessing goods without using (consuming) them. Given that this motive is most important among elderly people (for whom reverse mortgage is designed), it also should be taken into consideration: $U=f(c, w)$, where $w$ is a vector of goods, accumulated as heritage. For every time period an individual solves maximization problem

$$
\mathrm{L}=\mathrm{f}(\mathrm{c}, \mathrm{w})-\lambda\left(\text { As }-\mathrm{p}_{\mathrm{c}} \mathrm{c}-\mathrm{p}_{\mathrm{w}} \mathrm{w}\right)(11)
$$

Where $L$ is Lagrange function, $\lambda$ - Lagrange multiplier, As - volume of consumer's assets, $\mathrm{p}$ - price of good (with subscripts, indicating type of product).

Here, we should note, that, based on certain considerations, we have included assets in the formula (instead of income, as a standard variable). Our task implies that every period a consumer makes a choice: whether to spend their resources on consumption or bequest. In reality, property (that is often used as heritage) is illiquid and is bought less often than once a period. Therefore, we state the problem another way: individuals decide, whether to hold 
their assets as money for consumption or property for heritage. As a result, maximization provides an optimal bundle of goods $\left(\mathrm{c}^{*}, \mathrm{w}^{*}\right)$

Reverse mortgage affects optimum the following way: annuity payments can be considered an increase to the overall volume of liquid assets that could be spent on consumption. Based on optimum good distribution, we can derive indirect utility function:

$$
\mathrm{V}\left(\mathrm{p}_{\mathrm{c}}, \mathrm{p}_{\mathrm{w}}, \mathrm{As}\right)=\mathrm{U}\left(\mathrm{c}\left(\mathrm{p}_{\mathrm{c}}, \mathrm{As}\right), \mathrm{w}\left(\mathrm{p}_{\mathrm{w}}, \mathrm{As}\right)\right)
$$

Where $\mathrm{V}$ is indirect utility. Then, with the help of Roy's Identity we can derive demand function:

$$
\mathrm{D}_{\mathrm{c}}=-\frac{\frac{\partial \mathrm{V}}{\partial \mathrm{p}_{\mathrm{c}}}}{\frac{\partial \mathrm{V}}{\partial \mathrm{As}}}
$$

Demand on normal goods increases with income growth. Therefore, in our case: $\frac{\partial \mathrm{D}_{\mathrm{c}}}{\partial \mathrm{As}}>0$

Note that an increase in liquid assets occurs originates from a decrease in illiquid (real estate value). Furthermore, because of existence of bank margin, for every period inequality $\sum_{t=1}^{T} A_{t}<L_{T}$ holds true. This inequality means that for any period size of the loan (which de facto decreases volume of individual's illiquid assets) is more than sum of annuities received. So, we can conclude that reverse mortgage decreases total volume of assets owned by a borrower. Nonetheless, it still can be beneficial for a borrower due to some specific property characteristics: illiquidity and indivisibility. Let us consider these characteristics with the help of the following example: consider a consumer that owns housing that is used as bequest and a place for living. Then a following situation may arise:

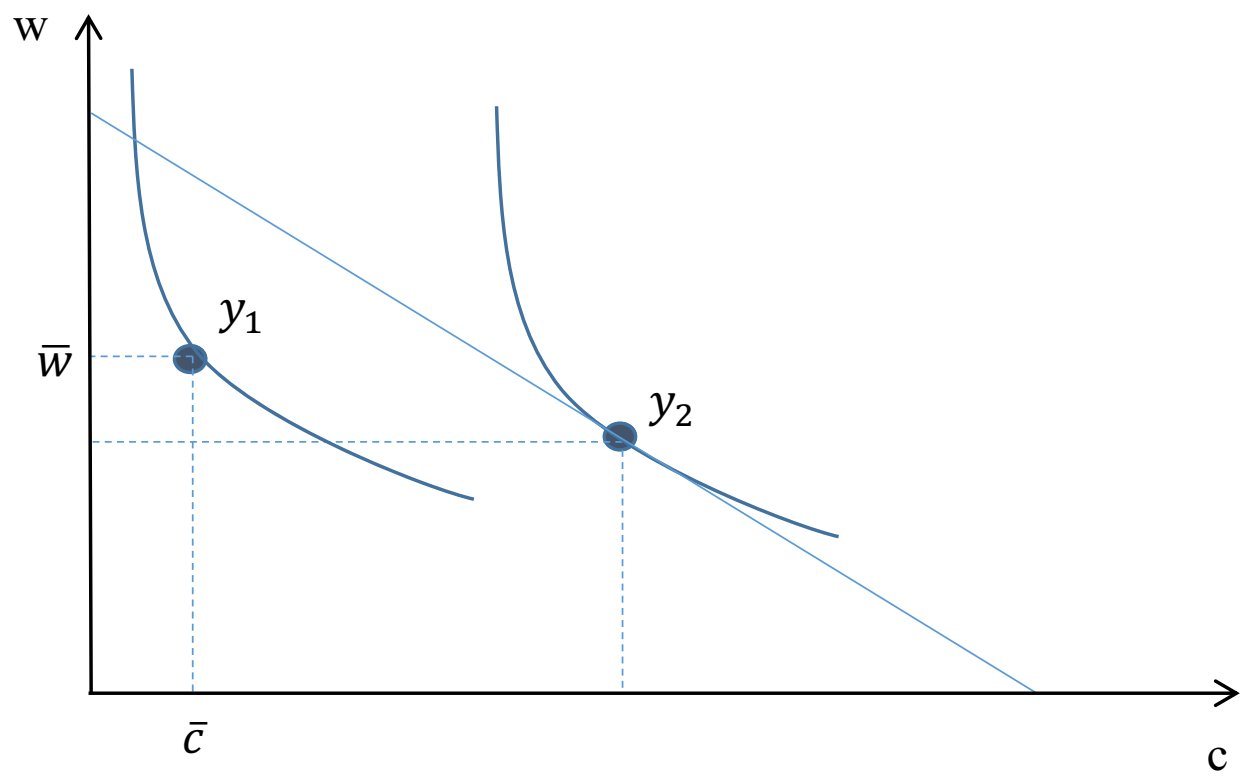

Fig. 1. Potential optimal allocation of goods 
Let us assume that an individual possesses initial good allocation $\overline{\mathrm{w}}, \overline{\mathrm{c}}$ corresponding to point $\mathrm{y} 1$. Then, the individual would prefer to exchange some amount of the good $\mathrm{w}$, in order to consume more $\mathrm{c}$ and move to point $\mathrm{y} 2$. This is where indivisibility effect appears: the consumer cannot sell only part of the housing: it is possible to sell either $\bar{w}$ or nothing. Therefore, point y2 (though being located on a budget constraint line) is unreachable because of indivisibility of a good. Moreover, the individual cannot sell in the current period the housing in order to buy a cheaper one, because of illiquidity characteristic. Now, we can consider an effect of the reverse mortgage:

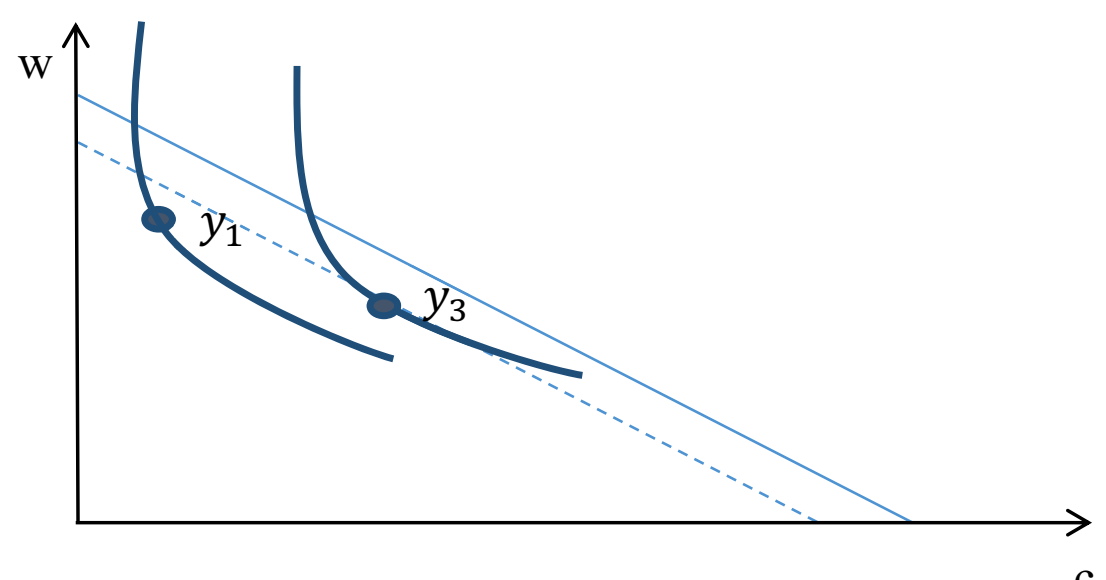

Fig. 2. Improved allocation of goods with the help of reverse mortgage

Reverse mortgage helps to avoid the mentioned restrictions, by making it possible to convert a part of property's value into money. Hence, an individual (with the help of reverse mortgage) is eligible to reach point $\mathrm{y} 3$, which yields more utility than initial allocation. Though, y3 is still worse than y2, because reverse mortgage decreases overall volume of individual's assets. Another advantage of reverse mortgage is the following: housing is not only an object of heritage, but also a good of consumption (since an individual gains some additional utility while living in a house, rather than on a street). Given that reverse mortgage does not prohibit a borrower to live in a house that is being used as a lien, the borrower does not lose the utility [Cox et al., 2015; Davidoff, 2015].

Now, we can derive a formula for a condition of participation in reverse mortgage program:

$$
\begin{array}{r}
E(G)=\sum_{t=0}^{T}\left(1-\psi m_{t}\right)(1+\rho)^{-t} *\left(U(c(A s+A))-U(c(A s))-\sum_{t=0}^{T} \psi m_{t}(1+\rho)^{-t}\right. \\
*\left(U\left(w\left(h_{t}\right)\right)-U\left(w\left(h_{t}-L_{t}\right)\right)-\sum_{t=a g e+T}^{E(l)} U\left(c\left(\tilde{h}_{t}\right)\right)\left(1-\psi m_{t}\right)(14)\right.
\end{array}
$$

Where $\rho$ is a subjective consumer's discount rate, $h_{t}-$ market value of a property in period $t, U\left(\tilde{h}_{t}\right)$ - utility of possessing a property in period t. Formula (14) represents an expected gain; condition of participation is $\mathrm{E}(\mathrm{G}) \geq$ alternative gain, or, if other alternatives are invalid or not profitable, $E(G) \geq 0$. Possible alternatives are: sell the property, take a loan and etc. We can inspect the formula more precisely:

- The first member of a formula represents gain from reverse mortgage. Specifically, reverse mortgage provides borrowers with annuity payments that can 
be spent on consumption. These gain are discounted and multiplied by a probability of surviving in period $t$.

- Second member represents utility losses (from the point of view of heritage motive) from taking reverse mortgage. The losses here consist of loan size (also multiplied by probability and discounted).

- Third member is losses of utility from not living in a housing. This part of the equation is valid only in case if reverse mortgage is not life-long, but with a restriction (for instance, as it was discussed in chapter 1, some reverse mortgage loans in US have duration limitation of 30 years). In this case, if individual lives longer than reverse mortgage duration he/she loses the housing and stops receiving utility from it.

There are certain factors which increase chances that reverse mortgage will be profitable for a borrower:

1. $\operatorname{MU}(\overline{\mathrm{c}}) \gg \operatorname{MU}(\overline{\mathrm{w}})$ if marginal utility of consumption is considerably bigger (in initial allocation point) than marginal utility of heritage accumulation, then reverse mortgage could be beneficial. In reality this could happen, if, for instance, an individual does not have close relatives.

2. Small value of mortality rate: it is evident that $\frac{\partial \mathrm{E}(\mathrm{G})}{\partial \mathrm{m}}<0$. Therefore, a consumer would like to convert property into money, if he/she lives long enough to use the obtained liquid financial resources for consumption. This also goes well in line with banks' demands: loan size also enlarges with increased individual's lifespan. Surprisingly, but this may lead to emergence of unique situation - positive selection (in contrast with adverse selection that often arises on markets with asymmetric information).

Similarly to formula (14), we can build a motivation condition for a bank:

$$
\begin{gathered}
E(\pi)=D *\left[(1-p) A\left(\frac{\left(1+\frac{i}{12}\right)^{n}-1}{1-\frac{1}{1+\frac{i}{12}}}-n\right) * \frac{1}{n} \sum_{t=0}^{n-1} \frac{1}{(1+r)^{\frac{t}{12}}}-p\left(\widehat{L_{b}}-h_{T}\right) * \frac{1}{(1+r)^{\frac{\hat{n}}{12}}}\right. \\
- \\
\left.d-C_{o}\right] \geq N\left(B \hat{r} * \sum_{t=1}^{n-1} \frac{1}{(1+r)^{\frac{t}{12}}}+\frac{(1+\hat{r}) B}{(1+r)^{\frac{n}{12}}}\right)-N B(15)
\end{gathered}
$$

Where $\mathrm{B}$ is bond nominal price, $\hat{\mathrm{r}}$ - bond's monthly yield rate, $\mathrm{N}$ - number of bonds purchased, D - quantitative measure of demand. Traditionally, profitability of a project is compared to profitability of riskless investment. Government bonds are often regarded as riskless investments. Hence, expected profit gained from reverse mortgage should more or equal bond yields, so that a bank would be interested in issuing reverse mortgages. As for the demand, we may express it in the following formula:

$$
\left.\mathrm{D}=\mathrm{Q} \varphi *\left(1-\mathrm{F}_{\mathrm{G}} \text { (alternative }\right)\right)-\mathrm{Z}
$$

Where $\mathrm{Q}$ is number of households that consist of people with eligible for reverse mortgage age, $\varphi$ - share of households with appropriate property, $F_{G}$ - distribution function of pure gains of consumers, $\mathrm{Z}$ - some constant which indicates that not all people will be choosing reverse mortgage, even if it would be profitable for them (this constant may be having several interpretations; f.e. - level of economic rationality of subjects). 
Optimal choice of bank may be derived from formula (15) by differentiating it (by interest rate):

$$
\begin{gathered}
\frac{\partial E(\pi)}{\partial i}=\frac{\partial D}{\partial i} *\left[(1-p) A\left(\frac{\left(1+\frac{i}{12}\right)^{n}-1}{1-\frac{1}{1+\frac{i}{12}}}-n\right) * \frac{1}{n} \sum_{t=0}^{n-1} \frac{1}{(1+r)^{\frac{t}{12}}}-p\left(\hat{L}-h_{T}\right)\right. \\
* \frac{1}{(1+r)^{\frac{\hat{n}}{12}}}- \\
\left.-C_{o}\right]+D *\left[(1-p) A * \frac{1}{n} \sum_{t=0}^{n-1} \frac{1}{(1+r)^{\frac{t}{12}}} * \frac{(-12+n i) *\left(1+\frac{i}{12}\right)^{n}+12}{i^{2}}-\frac{p A}{(1+r)^{\frac{\hat{n}}{12}}} *\right. \\
\left.* \frac{(-12+\hat{n} i) *\left(1+\frac{i}{12}\right)^{\hat{n}}+12}{i^{2}}\right]
\end{gathered}
$$

An interest rate is the main variable in the current model which can be affected by a bank. Therefore, being an economic agent, bank will be maximizing its profit by altering the interest rate i. Consequently, with the help of using first order condition, having defined the exogenous parameters, a bank can derive optimal rate from formula (17) by equaling it to 0 . Also, formulas (16) and (17) together define market equilibrium point: a bank, having all the information about the market, sets interest rate for the reverse mortgage and the consumers exhibit demand on a product (according to their utility functions) depending on an interest rate.

\section{Discussion}

The presented mathematical framework fulfills the initial goal set at the beginning of the paper. Nonetheless several adjustments could be made in order to make it more usable in different situations. First possible adjustment is to adjust formula for line of credit loans. Line of credit could be an attractive specification for those pensioners that have a permanent source of income, but also experience considerable irregular costs (connected with health issues, for example); hence, this specification may be demanded at the market. The issue of modelling line of credit is that these payments are irregular and made on demand: a borrower may request payment at any time, while the loan is still active. Therefore, calculation of expected gains is disturbed by a fact that the overall loan volume depends not on mortality rates that could be derived statistically, but solely on client's desire to borrow. This makes modelling of such loans an unordinary task, since a new probabilistic member (probability of a borrower to borrow a sum of money) arises, increasing overall uncertainty. However, instead of trying to model this highly volatile type of loans, we may address the issue itself and propose possible reverse mortgage loan specifications that diminish the uncertainty. Another possible adjustment is connected with variable interest rates. In current case, the bank sets one rate for the whole credit period, but contemporary reverse mortgage loans often use variable rates tied to some indices (e.g. LIBOR or EURIBOR). Variable rate is considered to be a tool of risk management that secures future payments from possible interest rate rises. In case of variable rate, it is necessary to forecast future index rates to provide insights on future interest rate value (that directly affects bank's expected gains). One way to performs this is to use time-series modelling to predict index values. 
Another possible focus for future research is to provide insights on how to calculate parameters present in the current work's formulas in real market situation. For example, in order to complete the calculations banks, need a value of the market demand (formula 16); it may be a difficult task to obtain this value for Russian market. So, providing banks with help and guidelines on how to obtain the parameters' values would increase the overall utility of the current study, as well as enhance usability of reverse mortgage loans.

\section{Conclusion}

In conclusion we want to outline again the importance of securing the welfare of unproductive (thus socially unprotected) population, who cannot earn enough money with their labor in order to fulfil their demands and live a worthy life [11]. Elderly people is the most numerous group of such people; therefore, they require most attention. In this paper we have studied a specific financial product aimed on increasing senior citizens' welfare reverse mortgage. We have inspected an experience of proposing reverse mortgage loans in other countries (especially the US) and have reached the conclusion, that this product may be highly demanded on Russian market [12].

Though reverse mortgage pursues a socially important objective, it is still a commercial product. Therefore, in order to introduce reverse mortgage to Russian market, banks require a framework that will allow to evaluate the expected gains from this loan type. So, the goal of the current work was to create a mathematical model that would allow to calculate expected profits under different circumstances and parameters. We have created this model by combining the equations of incentives of different actors (profit equation for banks and utility equation for borrowers). As a result, an equation of expected profit maximization was produced. The equation consists only of exogenous parameters (like borrower's property value, expected lifespan etc.) and variables, that the bank has direct control of (interest rates, annuity volume), thus creating a framework that allows to calculate gains, providing an opportunity for profit maximization management. This creates initial guidelines for the banks that might consider issuing reverse mortgages, what enhances the applicability of this financial instrument on Russian market.

\section{References}

1. H. Chen, S.H. Cox, S.S. Wang, Insurance: Mathematics and Economics, 46 (2), 371$384(2010)$

2. R. Cox, D. Brounen, P. Neuteboom, The Journal of Real Estate Finance and Economics, 50 (1), 74-112 (2015)

3. Consumer Financial Protection Bureau. Reverse mortgages. In Report to Congress, US Government, 2012

4. T. Davidoff, The Review of Financial Studies, 28 (8), 2364-2398 (2015)

5. S.G. Kellison, The theory of interest (Inc., Homewood, Illinois, 2006)

6. 6. A. Kogure, J. Li, S. Kamiya, North American Actuarial Journal, 18 (1), 242-257 (2014)

7. 7. Y.T. Lee, C.W. Wang, H.C. Huang, Insurance: Mathematics and Economics, 51 (2), 430-441 (2012)

8. L.M. Lockwood, Review of economic dynamics, 15 (2), 226-243 (2012)

9. M. Nakajima, I.A. Telyukova, The Journal of Finance, 72 (2), 911-950 (2017)

10. A.W. Shao, K. Hanewald, M. Sherris, Insurance: Mathematics and Economics, 63 76-90 ( 2015) 
11. O. Panfilova, V. Okrepilov, S. Kuzmina, MATEC Web of Conferences, 17001032 (2018) https://doi.org/10.1051/matecconf/201817001032

12. E. Kouzmina, V. Okrepilov, E3S Web of Conferences, 11001028 (2019) DOI: https://doi.org/10.1051/e3sconf/201911002034 